Inquiry

An Interdisciplinary Journal of Philosophy

ISSN: 0020-174X (Print) 1502-3923 (Online) Journal homepage: http://www.tandfonline.com/loi/sinq20

\title{
A sound Cartesian Argument from Doubt for dualism
}

\section{Ari Maunu}

To cite this article: Ari Maunu (2018) A sound Cartesian Argument from Doubt for dualism, Inquiry, 61:4, 461-465, DOI: 10.1080/0020174X.2016.1210020

To link to this article: https://doi.org/10.1080/0020174X.2016.1210020

$$
\text { 曲 Published online: } 28 \text { Jul } 2016 .
$$

Submit your article to this journal ¿त

Џlll Article views: 517

Q View related articles $\widetilde{ }$

View Crossmark data $\nearrow$ 


\title{
A sound Cartesian Argument from Doubt for dualism
}

\author{
Ari Maunu \\ Department of Philosophy, University of Turku, Turku, Finland
}

\begin{abstract}
I put forward a version of the Cartesian Argument from Doubt for mindbody dualism. My version utilizes de re statements, which means that it is not vulnerable to the usual charge of intensional fallacy. The key de re statement is, 'Body is such that its existence is entailed by Mind's believing that Body does not exist', which is false, whereas the respective 'Mind is such that its existence is entailed by Mind's believing that Body does not exist' is true.
\end{abstract}

ARTICLE HISTORY Received 1 March 2016; Accepted 29 June 2016

KEYWORDS Dualism; Descartes; intensionality; de re

Descartes's Argument from Doubt for mind-body dualism is, roughly, the following: Because one cannot (rationally) doubt the existence of one's mind but can (rationally) doubt the existence of one's body, it follows that one's mind is numerically distinct from one's body. ${ }^{1}$ My purpose in this paper is to challenge the received view that arguments of this kind fail, by suggesting a valid and sound modified version of the Cartesian Argument, with de re readings of the relevant statements about the mind and the body.

Before going into my version of Descartes's Argument, I need to make clear the distinction between de dicto and de re. It is basically a scope distinction that may be characterized roughly by saying that in a de dicto statement, but not in a de re statement, the relevant term occurs within the scope of an intensionality-producing verb or operator. More precisely, let us call the position of a singular term ' $b$ ' in a statement in which occurs, extensional if the following substitutivity principle (PS) holds for good:

CONTACT Ari Maunu arimaunu@utu.fi

'Descartes 1986, 518 / Descartes 1984, 412:'I ... am not a body. Otherwise, if I had doubts about my body, I would also have doubts about myself, and I cannot have doubts about that.' Similar passages appear in Discourse on the Method (Part IV, par. 2) and Meditation II. 
(PS) If in a true statement (or sentence) a singular term 'b', occurring in a certain position in this statement, is replaced by (substituted with) a singular term coreferential with it (i.e. with a term having the same referent $a s^{~ ' ~} b$ '), a true statement (sentence) results.

A position for which (PS) does not hold (in general) is called intensional. A statement is a called a de dicto (de re, respectively) statement with respect to a position (or occurrence of a singular term) when the position (of this occurrence) is extensional (intensional, respectively).

Utilizing lambda abstraction, the de re statement ' $\lambda x(F x) b$ ' - or, equivalently, ${ }^{\prime} \exists x(b=x \& F x)^{\prime}$ - may fail to be equivalent with the de dicto statement ' $F b$ ', because the position of ' $\mathrm{X}$ ' in ' $\mathrm{Fx}$ ' may be intensional. For example, $b$ may be such that it is believed by somebody, s, to be a $G$ (or, $\lambda x\left(B_{s} G x\right) b-$ de re), without it being true that $s$ believes that $b$ is a $G$ (or, $\mathrm{B}_{\mathrm{s}} \mathrm{Gb}$ - de dicto).

It is customary to put forth that the distinctness conclusion in the Argument from Doubt is reached by an application of Leibniz's Law (of the indiscernibility of identicals) - if $b=c$, then whatever is true of $b$ is true of $c$ (and vice versa, whatever is true of $\mathrm{c}$ is true of b). However, in order to avoid certain complications and misunderstandings connected with this principle, I shall utilize only the following incontestable principle of substitutivity in extensional positions:

(PSE) If singular terms ' $b$ ' and ' $c$ ' are co-referring and ' $b$ ' occurs in a sentence in an extensional position, then ' $b$ ' may be replaced truth-preservingly with ' $c$ ' in that position in that sentence.

The point to be utilized below is that in a de re statement the relevant term is in an extensional position. So, if ' $b$ ' and ' $c$ ' are co-referring and ' $\lambda x\left(B_{s} G x\right) b$ ' is true, then, by PSE, ' $\lambda x\left(B_{s} G x\right) c$ ' is true as well. (Note that ' $b$ ' and ' $c$ ' may be any terms that (purport to) refer to or designate an individual, even definite descriptions.)

Proceeding then into my modification of the Argument from Doubt, I take it for granted that we can say that minds have mental states such as believing. Let us take as our example a certain person who believes, mistakenly, that his body does not exist. Call his mind 'Mind' and his body (or brains) 'Body'. Since a nonexistent mind (as it were) could not believe anything, it seems evidently true that

(1*) Mind is such that its existence is entailed by Mind's believing that Body does not exist, ${ }^{2}$ 
or,

(1) $\lambda x\left(B_{m} \sim E b \Rightarrow E x\right) m$,

where ' $m$ ' stands for Mind, ' $b$ ' for Body, ' $E$ ' for existence ${ }^{3}$ and ' $\Rightarrow$ ' for entailment.

Assume, for reduction, that

(2) ' $m$ ' and 'b' are co-referring.

It follows from (1) \& (2) by PSE that

(3) $\lambda x\left(B_{m} \sim E b \Rightarrow E x\right) b^{4}$

that is,

$\left(3^{*}\right)$ Body is such that its existence is entailed by Mind's believing that Body does not exist.

Arguably, this is false: There is no such true entailment claimed in (3) as there is in (1). Therefore, since (1) is true, the assumed co-reference of 'Mind' and 'Body' is false. ${ }^{5}$ That is, dualism is confirmed: The mind is numerically distinct from the body.

The standard objection to Descartes's Argument from Doubt is that it commits the intensional fallacy: the argument is compared (for example) to the obviously mistaken derivation of distinctness from, say, Alan's believing that Orwell is a writer and not believing that Blair is a writer. It is often thought that Descartes makes such a mistake in his version of the argument. No such fallacy is committed in the present version: the positions of relevant singular terms are extensional.

Secondly, even Leibniz Law is sometimes denied: Jacquette (2011) does so in connection with Descartes's Argument. To my mind this is preposterous but in any case that Law isn't utilized in the argument of this paper, only the indisputable PSE.

Thirdly, Paul M. Churchland, for example, might claim that my version of the argument begs the question. Churchland $(1988,33)$ gives the following version of the Cartesian argument:

$\left[\left(4^{*}\right)\right]$ My mental states are knowable by introspection.

$\left[\left(5^{*}\right)\right]$ My brain states are not knowable by introspection.

Therefore, by Leibniz' Law,

${ }^{3}$ This is not a place to ponder over the question whether 'existence is a predicate'.

${ }^{4}$ Note that if a singular term occurs in a sentence in two (or more) positions, a salva veritate substitution need not be uniform (in these positions) - cf. (PSE). Since (1) is of the form Smm, with both m's in extensional positions, (3), being of the form Smb, is justified by (PSE).

${ }^{5}$ Of course, Leibniz's Law works here as well: If (1) is true and (3) is false, then 'Mind = Body' is false. 
$\left[\left(6^{*}\right)\right]$ My mental states are not identical with my brain states.

He admits that being knowable by introspection is 'a genuine property of a thing' - that is, I gather, that the first two sentences are to be construed as de re statements - but insists that the proponent of this argument begs the question in taking the second sentence as true: 'For if mental states are indeed brain states, then it is really brain states we have been introspecting all along, though without fully appreciating what they are' (Churchland 1988, 33).

Now, writing ' $\mathrm{K}$ ' for 'knowable by introspection', the argument above, as I understand it, is as follows:

(4) $\lambda x(K x) m$

(5) $\sim \lambda x(K x) b$

$\therefore(6) \mathrm{m} \neq \mathrm{b}$

Churchland's objection is that the dualist begs the question because this argument can be turned around to yield (4) $\& \sim(6) / \sim(5)$. And he is right: The dualist seems to have no independent support for the claim that (5), rather than $\sim(6)$, is true.

In general, an argument of the form $\mathrm{p} \& \mathrm{q} / \mathrm{r}$ can always be reversed into $p \& \sim r / \sim q$. Then sometimes the very heart of the matter is whether $q$ or $\sim r$ should be accepted, or whether the proponent of the first argument or the proponent of the second is begging the question. And it is inherent in the Cartesian Argument that the monist opponent can claim that accepting a premise like (5) or the negation of $(3) /\left(3^{*}\right)$ begs the question against the identity theory.

However, in the case of my version of the argument, we have, corresponding to $\sim(5)$,

$\left(3^{*}\right)$ Body is such that its existence is entailed by Mind's believing that Body does not exist.

(3) $\lambda x\left(B_{m} \sim E b \Rightarrow E x\right) b$.

The falsity of this does have some independent support: There appears not to be such entailment as claimed in (3). In short, my version turns on the entailment that definitely holds for Mind and certainly appears not to hold for Body. Hence, if the identity theorist objects my argument in the manner Churchland counters (4) \& (5) / (6) - i.e. by merely stating that if $\mathrm{m}=\mathrm{b}$ then (5) is false - it is he or she who begs the question.

\section{Disclosure statement}

No potential conflict of interest was reported by the author. 


\section{References}

Churchland, Paul M. 1988. Matter and Consciousness: A Contemporary Introduction to the Philosophy of Mind. Revised ed. Cambridge, MA: MIT Press.

Descartes, René. 1986. Oeuvres de Descartes. Vol. X. Edited by Charles Adam, and Paul Tannery. Paris: Librairie Philosophique J. Vrin.

Descartes, René. 1984. The Philosophical Writings of Descartes. Vol. Il. Translated by John Cottingham, Robert Stoothoff, \& Dugald Murdoch. Cambridge: Cambridge University Press.

Jacquette, Dale. 2011. "Descartes' Arguments for the Mind-Body Distinction." In Just the Arguments: 100 of the Most Important Arguments in Western Philosophy, edited by M. Bruce and S. Barbone, 290-296. Oxford: Blackwell. 